\title{
VIOLENCIA Y MIEDO EN \\ LA CIUDAD: LA CASA QUE HABITAMOS DE ARIEL BARRÍA ALVARADO
}

\author{
Humberto López Cruz \\ University of Central Florida \\ https://doi.org/10.18778/8220-195-6.26
}

\begin{abstract}
Una ciudad, previamente a su aparición en la realidad, debía existir en una representación simbólica que obviamente sólo podían asegurar los signos: las palabras, que traducían la voluntad de edificarla en la aplicación de normas y, [...], los diagramas gráficos, que las diseñaban en los planos [...]. Pensar la ciudad competía a esos instrumentos simbólicos que estaban adquiriendo su presta autonomía, la que los adecuaría aún mejor a las funciones que les reclamaba el poder absoluto.
\end{abstract}

(Rama, 1984: 16)

\section{Resumen}

La ciudad, a través de los tiempos, ha sido el lugar idóneo para las confluencias; un sitio donde se intenta una posible intersección de pensamientos y donde, al unísono, se establecen las más encarnizadas controversias. La metrópoli, en su esperada postura tradicional, es fundamental a la hora de autenticar a unos personajes que dependen de este dispositivo urbano para que el lector acepte su legitimidad; de otra forma, la credibilidad del entramado imaginativo sería puesta en duda. Además, es novedoso que este decorado que ofrece el novelista panameño, Ariel Barría Alvarado, con factores discursivos como la 
violencia y el miedo, presente una urbe que a pesar de parecer que actúa en contra del individuo, sea una zona que rescata una comunión de procederes y, por lo tanto, amigada con el personaje.

Palabras clave: Ariel Barría Alvarado, ciudad, literatura panameña, miedo, violencia textual.

La ciudad, a través de los tiempos, ha sido el lugar dispuesto para las confluencias; un sitio donde se intenta una posible intersección de pensamientos y donde, al unísono, se establecen las más encarnizadas controversias. Es el espacio en que se da cita un número considerable de los grupos sociales que conforman una nación; es fácil describir el enfrentamiento de una amplia variedad de personajes que van a narrar, juntos o por separado, un momento cualquiera de lo que constituye el acaecer cotidiano. La literatura ha recurrido con asiduidad al auxilio que implícitamente ha brindado la ciudad, con sus múltiples emplazamientos, para urdir tramas que, de otra forma, no hubiesen contado con la autenticidad requerida en discursos que necesitaban el espaldarazo citadino. Es por ello que las urbes se construyen a partir de la palabra, de la presencia de sus ciudadanos; son apuntalamientos de algo que va más allá de lo que se percibe a simple vista: es un esfuerzo generacional que se asienta en su pasado y pavimenta el camino hacia lo que vislumbra como futuro.

Este es el caso del escritor panameño contemporáneo, Ariel Barría Alvarado (1959)1, en La casa que habitamos (2007). Es importante resaltar que en esta ocasión, la ciudad ha desempeñado un papel secundario, pero estos roles que a simple vista no sue-

1 Ariel Barría Alvarado tiene otras publicaciones en su haber literario. Al redactar estas líneas, y además de La casa que habitamos (2007, premio Ricardo Miró en 2006), ha publicado las novelas La loma de cristal (2001) y Las canciones que el público nos pide (2015); a su vez, las colecciones de cuentos El libro de los sucesos (2000), Al pie de la letra (2003), En nombre del siglo (2004), Ojos para oír (2007) y Losa doce (2016). Hay que resaltar que las otras dos novelas señaladas también resultaron merecedoras del Ricardo Miró (2000 y 2014 respectivamente), así como su cuentística Ojos para oír (2006) y Losa doce (2015). 
len despertar mucho interés resultan ser de marcada envergadura a la hora de sopesar las posibles resoluciones que ofrece el autor. La metrópoli es fundamental a la hora de autenticar a unos personajes que dependen de este dispositivo urbano para que el lector acepte su legitimidad; de otra forma, la credibilidad del entramado imaginativo sería puesta en duda. Además, este decorado que ofrece Barría Alvarado presenta una urbe que, a pesar de parecer que actúa en contra del individuo, es posible que en el instante preciso acuda en su ayuda; es zona que rescata una comunión de procederes y, por lo tanto, amigada con el personaje.

Es cierto que el protagonismo citadino está limitado en la novela; hasta cierto punto aparece condicionado a la necesidad del personaje. Pese a esto, es una presencia que se hará notar y, a la sazón, será responsable del acontecer ficcional. A su vez, la ciudad podrá no regular el lenguaje de los personajes, pero sí va a orquestar el devenir de la trama. En La casa que habitamos, el autor comienza por mostrar un perfil hostil, una violencia textual que va a sentar tonos disonantes en la escritura y que va a rechazar la quimera de que será un enclave de acogida y refugio para quienes lo así buscaren. Por el contrario, la agresividad que asoma en los primeros capítulos sugiere que el conversatorio con el lector va a estar marcado por la polémica resultante de la fiereza a la que la ciudad expone a sus habitantes 2 .

En el prólogo de una sugestiva compilación sobre la violencia en las letras latinoamericanas, los editores remarcan lo que comenzaría este acercamiento a la novela de Barría Alvarado, ya que "la violencia ha sido objeto de numerosas elaboraciones literarias

2 La violencia textual no es nueva en el andar literario del autor. En su momento comenté la sutileza con que, en uno de sus cuentos incluido en la colección Al pie de la letra, asociaba el recuerdo de Babilonia con la inexorable destrucción de sus protagonistas. "La mención, más de una vez, de la legendaria ciudad abatida anticipa la destrucción de ambos personajes. Barría Alvarado es consciente de la manipulación sostenida y avanza en el recuerdo del narrador aproximándose al desenlace" (López Cruz, 2006: 46). Los interesados pueden consultar este artículo ya que aparece en las obras citadas. 
y fílmicas, así como reflexiones por parte de la historiografía y la filosofía. En cualquier caso, se trata de formas de interpretar las lógicas sociales y culturales que llevaron a esos casos de violencia" (Amar Sánchez, Avilés, 2015: 10). Tras este preámbulo, es obligado recurrir a la palabra autorizada para constatar cómo el autor organiza una retícula de imágenes que proyectan el campo visual requerido y así encajar la primera pieza de las muchas que harán falta para armar su rompecabezas discursivo:

...el mar se extendía, con la tersa y provocadora lozanía de un vientre amando hasta lo infinito. Era la suya una bella y próspera ciudad, corroída por un sinfín de escándalos, sí, pero hermosa y pujante como pocas, y ahora a él le tocaría compartir las decisiones que sobre ella se adoptaran en la cúpula del poder (Barría Alvarado, 2012: 12).

El nudo escritural se asienta en unas coordenadas geográficas que refieren la tensión socio-política, admítase también la siempre presente violencia, que conferirá veracidad a la narrativa y contribuirá a subrayar el aducido limitado protagonismo del entorno.

Para comenzar el desmontaje crítico se impone considerar el título. De por sí la frase, presidida por el sustantivo "casa" y unida al verbo "habitar" pluralizado, sugiere una invitación al lector para, desde del primer capítulo, generar la complicidad necesaria y lograr así que aquel sea parte del texto. Se puede argüir que esto es una premisa indispensable para obtener un encuentro satisfactorio con cualquier lectura; es la aspiración que persigue cualquier autor cada vez que entrega el producto de su creación. Sin embargo, aquí se va un poco más lejos: es la casa en que habitamos y que, por consiguiente, inspira un considerable sentido de seguridad y acarrea la fuerza suficiente para que la proyección de amparo alcance al lector. En otras palabras, es el sitio, común al personaje y a quienes lo leen, donde se ubica un refugio implícito ante la violencia exterior.

El protagonista se da a conocer en el primer capítulo viviendo en un apartamento exclusivo localizado en un barrio privilegiado 
de la ciudad, y termina con su pareja en una lujosa mansión, muy por encima de lo que pudiera aspirar el individuo promedio: "flanqueada por árboles casi centenarios, [...] era una casa grande, majestuosa, y ella iba a hacerla brillar como el hogar que siempre debió haber sido" (Barría Alvarado, 2012: 177). Los cuasi eternos árboles fundidos en la alegada majestuosidad de la vivienda (junto a la fastuosidad del apartamento introductorio) son accesorios que acercan a unas consideraciones de Gastón Bachelard cuando evoca que

El ser reina en una especie de paraíso terrestre de la materia [...]. Parece que en ese paraíso material, el ser está impregnado de una sustancia que lo nutre, está colmado de todos los bienes esenciales.

Cuando se sueña en la casa natal, en la profundidad extrema del ensueño, se participa de este calor primero, de esta materia bien templada del paraíso material. En este ambiente viven los seres protectores (Bachelard, 2000: 30).

La transición presentida y experimentada por los personajes, englobada por la casa que habitamos -ya incluido el lector en la pluralidad de la conjugación-, recurre a una materia que se desplaza entre dos viviendas para ofrecer la indubitable firmeza de un reducto no permeable; el personaje tiene que sentirse aislado de la violencia que lo rodea. O sea, en ambas instancias, la casa ha probado ser el intersticio idóneo que alberga la seguridad requerida por el individuo para desechar cualquier amenaza proveniente del exterior; son los espacios donde no hay cabida para el temor. Como queriendo destruir estas reflexiones, en el caso de esta novela de Barría Alvarado nada podría estar más lejos de la verdad.

En La casa que habitamos, la violencia se articula dentro de la zona protegida; una prueba indiscutible de que la ciudad ha extendido su poder hasta penetrar en el sitio de la intimidad. La metafórica casa se desteje para, una vez desdoblado el término y destruida la protección que emblematiza el concepto, transmutar la percepción preconcebida que el lector pudiera tener en una ampliación de la morada, del lugar que ha facilitado la tranquilidad 
necesaria a su habitante en el conglomerado citadino, en la metrópoli que funge ahora como hogar. Es significativo constatar que, salvo que estamos en una urbe capitalina latinoamericana, el autor no ofrece pistas directas que apuntarían a un país en específico; se podría especular el origen, pero en realidad carece de importancia para la finalidad de este artículo ${ }^{3}$. Las fronteras son continentales y no nacionales; no obstante, la agresividad del entorno marca a una sociedad que no requiere gentilicio propio para ubicarse en la región. Repasando una de las lógicas de desarrollo de Néstor García Canclini se ve que

las visiones despedazadas y la dificultad de abarcar íntegramente la vida en la ciudad han favorecido que en las teorías sobre lo urbano, sobre todo en las corrientes posmodernas, se piense que las grandes ciudades son implanificables. Como huyendo de la complejidad estructural de las megalópolis, en los planes urbanos se intenta dinamizar sólo algunas zonas que se consideran planificables (García Canclini, 2004: 65).

La posible planificación no acepta delimitaciones donde se impute la seguridad del individuo como un factor determinante. La propuesta de García Canclini insinúa un desentendimiento de las zonas marginadas por parte del centro; Barría Alvarado parece seguir la sugerencia y trae a sus personajes a la vorágine de la capital: "había escapado de un infierno para entrar en otro, [...]. Con los primeros dólares ganados a pulmón en las casas de gente adinerada, pudo ir trayendo poco a poco a sus hermanos y a su madre a compartir una nueva forma de miseria, la urbana" para atestar un rotundo "juró por todos los santos no regresar jamás a la tierra en que fue tan infeliz” (Barría Alvarado, 2012: 32).

3 Hay que notar que Barría Alvarado indica que el dólar es la moneda que circula en su ciudad imaginaria (32). Dicha ciudad es una capital latinoamericana enclavada en la costa; el mar la baña. A su vez, hay una referencia a una Basílica de la Virgen del Carmen (26) que, si bien es popular en todas las comunidades hispanas, quizás podría acercarse mejor al espacio concebido por el autor para desarrollar su trama. 
A pesar de ser dos clases sociales muy disímiles las trazadas en esta aproximación crítica, cuentan con que la violencia es el eje discursivo que las maniata para lograr el fin común; al mismo tiempo, es el lector quien intuye que la fiereza del ambiente debe ser aceptada como fondo decorativo, no tan solamente de la novela sino de la actualidad de la región. No perturba que sea un factor repetitivo que se ramifique por variadas representaciones gráficas bajo la pretensión, errónea, que es el argumento que rige la trama; otros temas pueden consolidarse como protagónicos tras una lectura inicial. Sin importar lo dicho, la ciudad en todo su esplendor clasista, político y erótico condiciona a sus ciudadanos hasta asentarlos en el molde para el cual fueron imaginados por el autor. La violencia los determina y acerca, pero son círculos que aunque se estrechen no llegan a tocarse en ningún punto; de hacerlo, destruirían la marcada división social existente en las comunidades descritas y Barría Alvarado es muy consciente que este acercamiento, contando con la ficción que conlleva la escritura, no es un atrevimiento narrativo plausible.

A partir de estos puntos, sería aconsejable engarzar los ejemplos de violencia citados con un predicamento que se torna esencial a la hora de auspiciar un escrutinio la ciudad: los medios informativos. No es el propósito resaltar aquí la brutalidad de sucesos noticiosos, pero sí apuntar hacia su forma de difusión; o sea, una lógica cultural que interroga la contemporaneidad del colectivo que representa y que, hasta cierto punto, sirve. En La casa que habitamos compaginan grupos heterogéneos comunitarios; no se mezclan, pero interactúan. Jesús Martín-Barbero señala que "los diversos sectores sociales no sienten la ciudad desde las mismas referencias materiales y simbólicas"; a la vez, continúa con unas observaciones que reflejan aspectos presentes en la novela, puesto que

en la ciudad de los flujos comunicativos cuentan más los procesos que las cosas, la ubicuidad e instantaneidad de la información [...]. La imbricación entre televisión e informática produce una alianza entre velocidades audiovisuales en informacionales, entre innovaciones tecnológicas y hábitos de consumo (Martín-Barbero, 2004: 77). 
A simple vista, el avance se torna agresivo; es una violencia definidora de la realidad social, establece y respalda un enunciado reaccionario. Como es de esperar, una aserción de esta índole necesita el combustible proveniente de Barría Alvarado que alimente su desarrollo.

El autor fomenta el ambiente apropiado para que confluyan los sectores implicados y comulguen por medio de lo que comparten: el violento sensacionalismo que se da cita en la urbe. De ahí las insistentes llamadas que recibe el periodista de "la persona que solía ponerlo en la pista de esos casos notables en esa podrida ciudad repleta de casos notables para un diario amarillista como el suyo" (Barría Alvarado, 2015: 95). La notabilidad del suceso mezclada con la servitud aludida pone de manifiesto que la sociedad se va a nutrir de estas infusiones de tribalismo textual, pero más que como un signo de escape, va a ser una prueba de afirmación. En efecto, la violencia, donde quiera que se enraíce, ostenta una factura perenne al portador; desafía y desplaza la agresividad anterior, en forma de noticia, ya que: "se vio muy pronto sepultada por otro de los comunes escándalos que solían acaecer en la ciudad" (Barría Alvarado, 2015: 36). Barría Alvarado aborda la superficialidad de la ocasión sugiriendo, con marcada puntualidad, que la concatenación de ejemplos en los que aflore la agresividad no va a dirigir el curso a seguir; después de todo, su postura ha sido maniobrar entre una serie de desplazamientos, no reinventando la violencia, pero sí facilitando la imagen presencial. El lector ha tenido ante sí el diagrama que conecta los puntos; un esquema práctico en el que visualizar, mediatizar y contrarrestar la vocación argumentativa en la novela que, en algún momento, dejará de tener trascendencia y cederá su protagonismo a otro factor dialogal que amerite ser considerado.

Esa coyuntura ha llegado y toca, por no demandar un mejor vocablo, traer a colación el miedo como elemento recurrente. Alear violencia y miedo resultaría, a vuelapluma, una labor no complicada; el primer registro generaría el segundo. Ahora bien, habría que preguntarse si el proceso escritural ha arribado a amedrentar al lector por medio de una narrativa ya esperada y, por consiguiente, sin la sorpresa textual de un thriller, o el miedo se 
inscribe más allá de las páginas de la novela. La postura de este ensayo abogaría por esta segunda acepción; la región refleja un miedo que va más allá de la violencia cotidiana. Para comenzar este acápite, se repasarían las palabras de Benito Elías García cuando propone que el “....abuso de la violencia ha acabado por configurar en la literatura una imagen de la muerte como reina todopoderosa, como huésped no invitado pero presente en todas las comunidades, que extiende sus garras hacia cualquier ámbito de la realidad" (García, 2013: 351). La casa que habitamos comienza con violencia y muerte; termina con muerte a causa de la violencia. La simbiosis está establecida y tal parece arrancada de la sección de sucesos de un diario local; de hecho, Barría Alvarado se sirve de este recurso para propeler los acontecimientos. Sin embargo, no es posible descartar el miedo antes y después de los eventos descritos; el autor adorna su entrega con la aprensión de quien sabe que es un tema escabroso, pero necesario. El protagonista facilita este entendimiento cuando expone que en sus pesadillas "corría al borde de un desfiladero, cubierto con harapos, huyéndole a la presencia acechante de un algo ominoso que le mordía las huellas" (Barría Alvarado, 2015: 20). Este temor se hace extensivo al resto de la población el cual, dependiendo de sus circunstancias individuales, comparte diversas jerarquías de miedo, pero siempre bajo la fachada del sobresalto de lo que se avecina.

La intimidación textual supera el campo de acción de los personajes, y cualquier posible alcance de la novela, para asentarse en la colectividad del sujeto dentro de la región ${ }^{4}$. El conglomera-

4 Refiriéndose a las letras panameñas, Ricardo Arturo Ríos Torres observa que "los narradores, poetas, dramaturgos y ensayistas hacen de lo absurdo y grotesco algo cotidiano y ellos con su realismo imaginativo, expresan la acción heroica de nuestro ser existencial" (Ríos Torres, 2016: 15). Al enmarcar la novela de Barría Alvarado dentro de este aserto de Ríos Torres se deduciría que lo absurdo es que el miedo visto en La casa que habitamos actúe como factor de integración textual al establecer una triple comunión: autor-lector-texto; pese a esta etiqueta de posible rechazo, se escuda la actualidad de la novela y la carencia de ubicación específica en la región. Como fuera señalado en una nota precedente, acaso fuese 
do social teme, pero también es una angustia compartida por el escritor. La "cara de terror" (Barría Alvarado, 2015: 40) con la que presenta al personaje sobrepasa la escena para representar la visión de todo un continente; es el resultado de la violencia comunitaria aludida que va a encontrar eco en la trama. En la narrativa, la ciudad, devenida continente, acusa rasgos que perturbarían a un lector foráneo, mas no a uno familiarizado con el hemisferio. Así y todo, el miedo literario de Barría Alvarado sobre lo que parece interminable se agudiza en los capítulos finales cuando concluye por medio de otro personaje que "el mal estaba carcomiendo las fibras íntimas de la sociedad” (Barría Alvarado, 2015: 172) para recaer en un receptor activo la madeja interpretativa que le toca deshilvanar, personaje o lector, ya que "sintió su angustia incrementándose a medida que el taxista que la conducía a la ciudad le detallaba los pormenores del caso, asegurándole con tono clarividente que este escándalo sí iba a significar el fin del gobierno, o del país, o de ambas cosas" (Barría Alvarado, 2015: 175). La premonición destructiva es, simbólicamente, la muerte citada de una ciudad, sociedad o región que no es capaz de detener el destino apocalíptico que anticipa el autor; de ahí que el miedo trascienda la maquinación atribuida. El telón de fondo puede o no haber limitado la disquisición crítica, pero sí ha contribuido a afincar unos preceptos de alerta que no deben ser subestimados; dicho de otra forma, los convencionalismos ya vistos han dado paso a una postura diferente, haciendo cogitar al lector local sobre la realidad de sus espacios.

En La casa que habitamos se conjuran los elementos pertinentes para que el relato convenza por su generalidad y se afiance en pos de un discurso que se sustenta de sus propias convicciones. Estas exigencias fuerzan a que la casa se convierta en ciudad y que ésta ampare la violencia, y el miedo que deriva, apuntalando así una visión más contemporánea de la región. Desde que el personaje "se enderezó en el asiento en el momento en que el taxi dejaba

Panamá la nación escogida, mas no está expresado con explicitud; por otra parte, sí se identifica el continente latinoamericano como el sitio donde se desenvuelve la trama. 
la autopista para ingresar a la urbe" (Barría Alvarado, 2015: 177) deja de ser un actante externo para dogmatizar su interacción con el texto; tiene que entrar, que ser parte del mismo; de otra forma, el autor no consentiría en utilizar su presencia como colofón a la agresividad vista. La ciudad, que pareció no disfrutar de una atención preponderante en el desarrollo de la trama, se ha erguido en su propia realidad para desafiar el reto impuesto por el autor y afirmar su presencia en un texto que no cesa de nutrirse de un emplazamiento identitario. Las lógicas de desarrollo argüidas anclan en el enunciado discursivo que aquí entrega el escritor comprobando, por este medio, el simbolismo augurado por Rama en el epígrafe y la actualidad de la narrativa. Esta es una ciudad que rescata, por medio de sus artificios, a aquellos que han sobrevivido el encuentro; el dinamismo citado va a planificar el desgarramiento estructural que supone pensar en las urbes en progreso de formación. Barría Alvarado proyecta el esquema y deja que el concurrir citadino violente a necesidad su engranaje novelístico.

\section{Bibliografía}

Amar Sánchez, A.M. y Avilés L.F. (2015). "Prólogo", en A.M. Amar Sánchez (ed.) y L.F. Avilés (ed.). Representaciones de la violencia en América Latina: genealogías culturales, formas literarias y dinámicas del presente, 9-21. Madrid y Frankfurt: Iberoamericana/Vervuert.

Bachelard, G. (1957). La poética del espacio, trad. Ernestina de Champourcin. México: Fondo de Cultura Económica.

Barría Alvarado, A. (2007). La casa que habitamos. Panamá: Géminis.

García, B.E. (2013). "La muerte viva: mito y violencia en América Latina”, en J.C. Rovira (ed.) y E. Valero Juan (ed.). Mito, palabra e historia en la tradición literaria latinoamericana, 349-364. Madrid y Frankfurt: Iberoamericana/Vervuert.

García Canclini, N. (2004). "El dinamismo de la descomposición: megaciudades latinoamericanas", en P. Navia (ed.) y M. Zimmerman (ed.). Las ciudades latinoamericanas en el nuevo [des] orden mundial, 58-72. México y Buenos Aires: Siglo XXI. 
López Cruz, H. (2006). "Una lectura de Al pie de la letra de Ariel Barría Alvarado”. Horizontes, 48/94, 41-48.

Martín-Barbero, J. (2004). "Mediaciones urbanas y nuevos escenarios de comunicación”, en P. Navia (ed.) y M. Zimmerman (ed.). Las ciudades latinoamericanas en el nuevo [des]orden mundial, 73-84. México y Buenos Aires: Siglo XXI.

Rama, A. (1984). La ciudad letrada. Montevideo: Comisión Uruguaya Pro Fundación Internacional Ángel Rama.

Ríos Torres, R.A. (2016). "Asedio a la historia contemporánea de Panamá”. Lotería, 525, 15-31. 